Check for updates

Cite this: RSC Adv., 2020, 10, 25352

Received 14th April 2020

Accepted 5th June 2020

DOI: $10.1039 / d 0 r a 03329 d$

rsc.li/rsc-advances

\section{An effective biocompatible fluorescent probe for bisulfite detection in aqueous solution, living cells, and mice $\uparrow$}

\author{
Ruqiao Zhou, (D) a Guiling Cui, ${ }^{\text {b }}$ Yuefu Hu, ${ }^{\text {b }}$ Qingrong Qi, ${ }^{\text {b }}$ Wencai Huang (D) ${ }^{c}$ \\ and Li Yang*a
}

Sulfur dioxide, an air pollutant, is easily hydrated to sulfites and bisulfites and extremely harmful to human health. On the other hand, endogenous sulfur dioxide is the fourth gasotransmitter. In view of the above, it is worth developing an effective method for the detection of these compounds. In this paper, a novel colorimetric fluorescent probe (Hcy-Mo), based on hemi-cyanine, for bisulfites is reported. Hcy-Mo shows excellent selectivity for bisulfites over various other species including cysteine, glutathione, $\mathrm{CN}^{-}$, and $\mathrm{HS}^{-}$, and undergoes 1,4-addition reactions at the $\mathrm{C}-4$ atom of the ethylene group. The reaction can be completed in $30 \mathrm{~s}$ in a PBS buffer solution and displays high sensitivity (limit of detection is $80 \mathrm{nM}$ ) for bisulfites. Test paper experiments show that the probe can be used for bisulfite detection in aqueous solutions. In addition, Hcy-Mo exhibits excellent cell permeability and low cytotoxicity for the successful detection of bisulfites in living MDA-MB-231 cells and in living mice, implying that this probe would be of great benefit to biological researchers for investigating the detailed biological and pharmacological functions of bisulfites in biological systems.

\section{Introduction}

Bisulfites are widely used in the food, beverage, and pharmaceutical industries as essential preservatives due to their antioxidation properties and ability to inhibit microbial growth and prevent discoloration. ${ }^{1,2}$ However, pathological studies have found that high concentrations of bisulfites are associated with inflammation, ${ }^{3-6}$ respiratory diseases, ${ }^{7}$ chromosomal aberrations, ${ }^{8,9}$ system diseases, ${ }^{10-13}$ and even cancer. ${ }^{14}$ On the other hand, sulfur dioxide, one of the most well-known air pollutants, ${ }^{15,16}$ can dissolve in water and form an equilibrium state between the sulfites and bisulfites. However, recently researchers have found that endogenous sulfur dioxide, which is present as bisulfites in vivo, is the fourth gasotransmitter similar to carbon monoxide (CO), nitrogen monoxide (NO), and hydrogen sulfide $\left(\mathrm{H}_{2} \mathrm{~S}\right){ }^{17,18}$ Thus, in view of the effects of the sulfites mentioned above and the significance of bisulfites in vivo, the intake of bisulfites by the human body must be limited.

${ }^{a}$ State Key Laboratory of Biotherapy and Cancer Center, West China Hospital, Sichuan University, Chengdu, Sichuan 610041, P. R. China. E-mail: yangli@scu.edu.cn; Fax: +86-159-2818-5249; Tel: +86-159-2818-5249

${ }^{b}$ West China School of Pharmacy, Sichuan University, Chengdu, Sichuan, 610041, China

'School of Chemical Engineering, Sichuan University, Chengdu, Sichuan, 610065, China

$\dagger$ Electronic supplementary information (ESI) available: Detailed synthesis, characterization (NMR, MS, etc.) of the probe. See DOI: 10.1039/d0ra03329d
Therefore, it is vital to find a fast and efficient method for in vivo bisulfite detection.

There are some conventional detection methods for bisulfites, such as colorimetry, titrimetry, chromatography, and electrochemical analysis. ${ }^{19-24}$ Unfortunately, it is difficult to apply these methods to endogenous bisulfite detection in real time due to the limitations of the methods and equipment. Recently, carbon dots, ${ }^{25,26}$ quantum dots, ${ }^{27,28}$ and fluorescencebased probes have emerged as fluorescent materials for biosensing. Among them, fluorescence-based probes are a promising class due to their non-invasiveness, high sensitivity, and high temporal and spatial resolution. ${ }^{29-33}$ At present, bisulfite fluorescent probes mainly include dinitrile alkenyl, ${ }^{34,35}$ dinitrile alkenyl analogs, ${ }^{36-38}$ aldehyde derivatives, ${ }^{39-41}$ and nitrocontaining compounds. ${ }^{42}$ However, these types of probes have some disadvantages, including a long response time, unsatisfactory limits of detection, and interference from biothiols, which limit their application. In contrast, hemi-cyanine has many advantages such as simple preparation, low cost, membrane permeability, organelle targeting and so on. ${ }^{43-45}$ Therefore, it is highly desirable to develop a novel fluorescent probe for biological samples. Many fluorescent probes have previously been reported in the literature, ${ }^{43,44,46-50}$ however, improvements are required for some properties. Therefore, an ideal fluorescent probe for in vivo bisulfite detection is still needed.

Herein, a fluorescent Hcy-Mo probe with naked eye recognition of bisulfites was designed and synthesized. Based on 
a biologically active hemi-cyanine and featuring a morpholine group, Hcy-Mo possessed good cell membrane permeability. The response mechanism can be verified by nuclear magnetic resonance spectroscopy (NMR), that is, the change in molecular conjugation due to the 1,4-addition reaction of the probe and bisulfites. Moreover, Hcy-Mo can be used to rapidly and specifically detect bisulfites in breast cancer cells and living mice.

\section{Experimental}

\section{Materials and instruments}

All of the chemical reagents and solvents were obtained commercially (Adamas Reagents or Cologne Reagents) and used as received without further purification unless otherwise stated. Ultrapure water was purified using a Millipore water purification system. Silica gel P60 (Qingdao, mesh number 200-300) was used for column chromatography. ${ }^{1} \mathrm{H}$ NMR and ${ }^{13} \mathrm{C}$ NMR spectra were recorded on a Bruker $400 \mathrm{M}$ instrument and chemical shifts are given in ppm using the peak of residual proton signals of DMSO- $d_{6}$ or $\mathrm{CDCl}_{3}-d_{6}$ as the internal standard. The mass spectra (ESI) were recorded on a Finnigan LCQ ${ }^{\text {DECA }}$ spectrometer with ESI mode. UV-Vis and fluorescence spectra were recorded on a SHIMADZU UV-2450 spectrophotometer and a VARIAN Cary Eclipse FL1003 M013 spectrometer, respectively. The fluorescence images of the MDA-MB-231 cells were recorded on an inverted fluorescence microscope (Olympus, Japan). The fluorescence images of the living mice were recorded on a Night OWL LB983 living imager.

All of the animal procedures were performed in accordance with the Guidelines for Care and Use of Laboratory Animals of Sichuan University and approved by the Animal Ethics Committee of Sichuan University.

\section{Synthesis of the probe Hcy-Mo}

As shown in Scheme 1, Hcy-Mo was prepared over three steps using 2,3,3-trimethylindolenine as the starting material. Structural identification of the products was confirmed by NMR and HRMS spectrometry.

A mixture of 4-morpholinebenzaldehyde (306 mg, $1.6 \mathrm{mmol}$ ), 2,2,3-trimethylsulfonium bromide (421 $\mathrm{mg}, 1.5 \mathrm{mmol}$ ), and anhydrous sodium acetate $(120 \mathrm{mg}, 1.5 \mathrm{mmol})$ in $6 \mathrm{~mL}$ of anhydrous acetic anhydride was refluxed at $85{ }^{\circ} \mathrm{C}$ for $1-2 \mathrm{~h}$ under a nitrogen atmosphere. The reaction was monitored by TLC. After completion, the mixture was cooled to room temperature and poured into a saturated brine solution. The

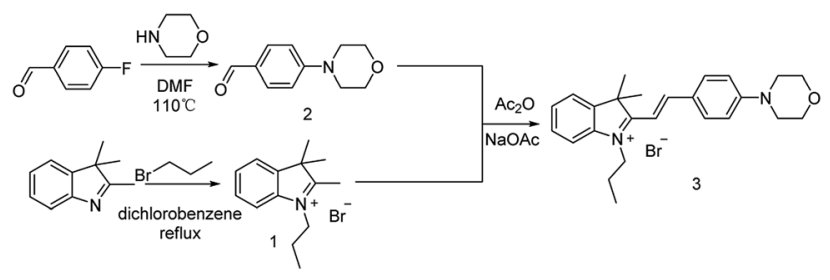

Scheme 1 Synthetic route to probe Hcy-Mo. product was extracted with dichloromethane 3 times. The combined organic phases were concentrated in vacuo. Then, $30 \mathrm{~mL}$ of isopropyl ether was added to the solution and the solution was filtered. The filter cake was washed 3-4 times with isopropyl ether. After that, the product was dried in vacuo to give a purple solid product $320 \mathrm{mg}$, yield $46.9 \%$. ${ }^{1} \mathrm{H} \mathrm{NMR}(400 \mathrm{MHz}$, DMSO- $\left.d_{6}\right) \delta 8.37(\mathrm{~d}, J=15.8 \mathrm{~Hz}, 1 \mathrm{H}), 8.13(\mathrm{~d}, J=8.7 \mathrm{~Hz}, 2 \mathrm{H})$, $7.81(\mathrm{t}, J=7.8 \mathrm{~Hz}, 2 \mathrm{H}), 7.57(\mathrm{t}, J=7.2 \mathrm{~Hz}, 1 \mathrm{H}), 7.52(\mathrm{t}, J=7.3 \mathrm{~Hz}$, $1 \mathrm{H}), 7.39(\mathrm{~d}, J=15.8 \mathrm{~Hz}, 1 \mathrm{H}), 7.11(\mathrm{~d}, J=8.7 \mathrm{~Hz}, 2 \mathrm{H}), 4.55(\mathrm{t}, J=$ $7.2 \mathrm{~Hz}, 2 \mathrm{H}), 3.75(\mathrm{t}, J=4.7 \mathrm{~Hz}, 4 \mathrm{H}), 3.51(\mathrm{t}, J=4.8 \mathrm{~Hz}, 4 \mathrm{H}), 1.85$ $(\mathrm{q}, J=7.3 \mathrm{~Hz}, 2 \mathrm{H}), 1.77(\mathrm{~s}, 6 \mathrm{H}), 1.00 \mathrm{ppm}(\mathrm{q}, J=7.5 \mathrm{~Hz}, 3 \mathrm{H}) .{ }^{13} \mathrm{C}$ NMR (100 MHz, DMSO- $\left.d_{6}\right) \delta 180.85,155.10,154.88,143.51$, 141.51, 134.45, 129.35, 128.51, 124.43, 123.37, 114.65, 113.89, 106.94, 66.27, 51.78, 47.10, 46.87, 26.89, 21.92, 11.27 ppm. ESIMS $m / z$ calcd for chemical formula: $\mathrm{C}_{25} \mathrm{H}_{31} \mathrm{~N}_{2} \mathrm{O}[\mathrm{M}]^{+}: 375.2191$; found: 375.2184 .

\section{Spectral experiment}

$0.91 \mathrm{mg}$ of the Hcy-Mo probe was dissolved in $2 \mathrm{~mL}$ of PBS solution to prepare a $1 \mathrm{mM}$ stock solution. The stock solution was then diluted to obtain a test concentration $(10 \mu \mathrm{M}) .2 .08 \mathrm{mg}$ of sodium bisulfite was dissolved in $2 \mathrm{~mL}$ of distilled water to prepare a $10 \mathrm{mM}$ stock solution, which was diluted to prepare the required test concentrations. Interfering ions were selected from different sodium salts ( $\mathrm{NaF}, \mathrm{NaCl}, \mathrm{NaBr}, \mathrm{NaI}, \mathrm{NaHCO}_{3}$, $\mathrm{Na}_{2} \mathrm{CO}_{3}, \mathrm{CH}_{3} \mathrm{COONa}, \mathrm{Na}_{2} \mathrm{~S}_{2} \mathrm{O}_{3}, \mathrm{Na}_{2} \mathrm{SO}_{4}, \mathrm{NaNO}_{2}, \mathrm{NaN}_{3}, \mathrm{NaSCN}$, cysteine, glutathione, tetrabutyl cyanamide, and NaHS) for the preparation of $20 \mathrm{mM}$ stock solutions. The stock solutions were diluted to the desired test concentration.

\section{Cytotoxicity and cell imaging}

A 96-well culture plate was inoculated with logarithmic growth phase cells. The cell suspension concentration in the culture dish was adjusted and the edge plate was filled with sterile PBS buffer and placed in an incubator $\left(5 \% \mathrm{CO}_{2}\right.$, temperature $\left.37^{\circ} \mathrm{C}\right)$. The culture was continued until the cell monolayer was spread over the bottom of the plate. The cells were divided into experimental groups and a control group. Hcy-Mo was not added to the control group. Different gradients of the probe Hcy-Mo solution were added to the experimental groups. After completion, the culture was placed in the incubator $\left(5 \% \mathrm{CO}_{2}\right.$, temperature $37{ }^{\circ} \mathrm{C}$ ). After $2 \mathrm{~h}, 10 \mu \mathrm{L}$ of the MTT solution was added to each well and the cells were incubated for 24 hours. The absorbance of each well was measured using a microplate reader and the cell survival rate was calculated.

Then, the medium in the well was replaced with a medium containing the probe (probe concentration: $10 \mu \mathrm{M}$ ). After incubation for $1 \mathrm{~h}$, the medium containing the probe solution was discarded and the cells were washed with sterile PBS 2-3 times to remove the non-incorporated cells. After that, the sodium bisulfite solution was added to each well and incubation was continued for $30 \mathrm{~min}$. Then, the sample was inverted under a microscope to observe and collect imaging data using the red fluorescent channel. 


\section{Mice imaging}

The Hcy-Mo probe $(50 \mu \mathrm{M})$ and the test substance sodium bisulfite $(500 \mu \mathrm{M})$ were prepared in PBS. The 24 hour fasting Kunming mice were divided into a blank group, control group and experimental group. The blank group was injected with PBS, the control group was injected with the probe, and the experimental group was injected with the probe and the test substance. Tail vein injection was adopted as the injection method in this study.

\section{Results and discussion}

\section{Design of Hcy-Mo}

A fluorophore is needed for the design of fluorescent probes. Hemi-cyanine has attracted attention for its mitochondrial targeting. ${ }^{51-55}$ In addition, morpholine is a good electron donor and exhibits lysosome-targeting. ${ }^{56,57}$ Thus, a mitochondrial targeting group is linked to a lysosome-targeting group by a " $\pi$ " bridge. We expect that the Hcy-Mo probe will show excellent biocompatibility and fluorescence response performances.

\section{Time response}

The absorption spectral properties of Hcy-Mo in the absence and presence of bisulfite in the buffer are shown in Fig. 1. When 10 equiv. of bisulfite was added, the maximum absorption of Hcy-Mo at $503 \mathrm{~nm}$ decreased remarkably and a new absorption peak at $280 \mathrm{~nm}$ increased gradually, with a well-defined isosbestic point at $320 \mathrm{~nm}$. At the same time, the color of the solution changed from brown to colorless, which could be seen by the naked eye. Moreover, the addition of sodium bisulfite also resulted in a remarkable decline in fluorescence at $596 \mathrm{~nm}$ upon excitation at $510 \mathrm{~nm}$.

\section{Sensitivity research}

The emission behavior of the Hcy-Mo probe $(10 \mu \mathrm{M})$ in the presence of bisulfite $(0,10,20,30,40,50,60,70,80,90$, and 100 $\mu \mathrm{M}$ ) was investigated, as shown in Fig. 2. The fluorescence intensity at $596 \mathrm{~nm}$ decreased with increasing bisulfite concentration. By plotting the fluorescence intensity of the HcyMo probe at $596 \mathrm{~nm}$ versus the concentration of bisulfite, a good linear relationship $\left(R^{2}=0.994\right)$ was obtained with concentrations ranging from 0 to $100 \mu \mathrm{M}$. The detection limit was calculated to be $80 \mathrm{nM}$ using the detection limit formula LOD =
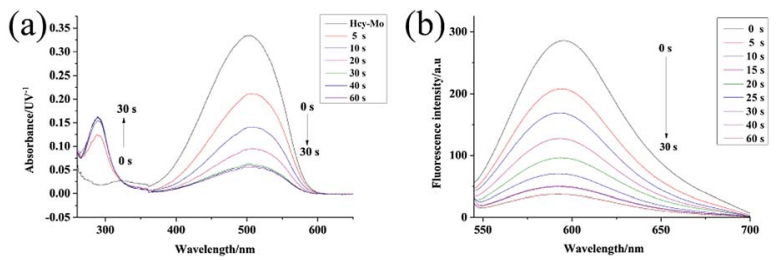

Fig. 1 Absorption (a) and fluorescence spectral (b) changes with the addition of the Hcy-Mo probe $(10 \mu \mathrm{M})$ in the absence and presence of sodium bisulfite (10 equiv.) in buffer solution (10 mM PBS, $\mathrm{pH}=7.4$ ) with $\lambda_{\text {ex }}$ of $510 \mathrm{~nm}$ at $25^{\circ} \mathrm{C}$.
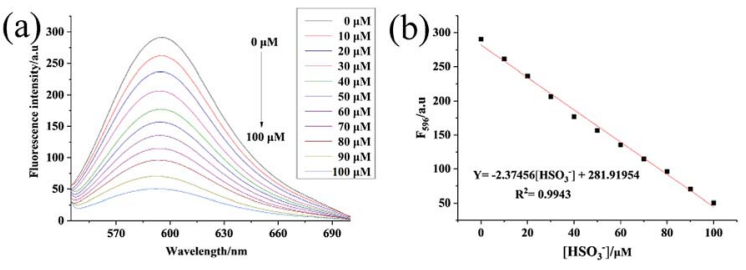

Fig. 2 (a) Fluorescence spectra of Hcy-Mo $(10 \mu \mathrm{M})$ upon the addition of increasing concentrations of sodium bisulfite $(0,10,20,30,40,50$, $60,70,80,90$, and $100 \mu \mathrm{M}$ ) when excited at $510 \mathrm{~nm}$ at $25^{\circ} \mathrm{C}$. (b) Fluorescence intensity changes of Hcy-Mo at $596 \mathrm{~nm}$ as a function of sodium bisulfite concentration.

$3 \delta / k$. It is worth mentioning that Hcy-Mo exhibited a high quantum yield $\left(\Phi_{\mathrm{F}}=0.22\right)$ in aqueous medium when excited at the $\lambda_{\max }(510 \mathrm{~nm})$ of Hcy-Mo.

\section{Selectivity tests}

Among all the factors, the selectivity of a probe is the most important one because of the complexity of biological samples. For this reason and on the basis of the above results, we further evaluated the selectivity of Hcy-Mo probe toward bisulfite over other relevant ions and amino acids including $\mathrm{NaF}, \mathrm{NaCl}, \mathrm{NaBr}$, $\mathrm{NaI}, \mathrm{NaHCO}_{3}, \mathrm{Na}_{2} \mathrm{CO}_{3}, \mathrm{CH}_{3} \mathrm{COONa}, \mathrm{Na}_{2} \mathrm{~S}_{2} \mathrm{O}_{3}, \mathrm{Na}_{2} \mathrm{SO}_{4}, \mathrm{NaNO}_{2}$, $\mathrm{NaN}_{3}$, NaSCN, cysteine, glutathione, tetrabutyl cyanide ammonium, and NaHS. As shown in Fig. 3, compared with many ions, only $\mathrm{HS}^{-}$exhibited a little decrease in the fluorescence intensity of Hcy-Mo. Furthermore, sodium bisulfite $(100 \mu \mathrm{M})$ caused a reduction in the Hcy-Mo $(10 \mu \mathrm{M})$ peak intensity at $596 \mathrm{~nm}$, which is a 5 -fold decrease compared with sodium hydrosulfide. Thus, the Hcy-Mo probe showed good selectivity towards bisulfite.

\section{pH stability}

In order to explore in vivo imaging potential, Hcy-Mo was placed under different $\mathrm{pH}$ conditions and the changes in fluorescence intensity at $596 \mathrm{~nm}$ with the absence and presence of bisulfite were measured. As shown in Fig. $\mathrm{S} 1, \uparrow \mathrm{pH}$ did not exert much influence on the fluorescence intensity of Hcy-Mo over the range of 7-9.
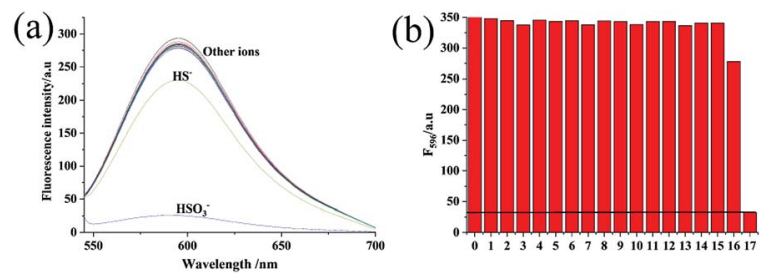

Fig. 3 (a) Fluorescence responses and (b) fluorescence enhancements at $596 \mathrm{~nm}$ of Hcy-Mo $(10 \mu \mathrm{M})$ to 10 equiv. of sodium bisulfite and 20 equiv. of interfering analytes ( $0: \mathrm{Hcy}-\mathrm{Mo}, 1: \mathrm{F}^{-}, 2: \mathrm{Cl}^{-}, 3: \mathrm{Br}^{-}, 4$ : $I^{-}, 5: \mathrm{HCO}_{3}{ }^{-}, 6: \mathrm{CO}_{3}{ }^{2-}, 7: \mathrm{CH}_{3} \mathrm{COO}^{-}, 8: \mathrm{S}_{2} \mathrm{O}_{3}{ }^{2-}, 9: \mathrm{SO}_{4}{ }^{2-}, 10: \mathrm{NO}_{2}{ }^{-}$, 11: $\left.\mathrm{N}_{3}^{-}, 12: \mathrm{SCN}^{-}, 13: \mathrm{CN}^{-}, 14: \mathrm{Cys}, 15: \mathrm{GSH}^{-16}: \mathrm{HS}^{-}, 17: \mathrm{HSO}_{3}^{-}\right)$. 


\section{Mechanism verification}

The detection mechanism of the Hcy-Mo probe toward bisulfite was speculated using data collected from ${ }^{1} \mathrm{H}$ NMR spectroscopy. As shown in Fig. 4, the quaternary ammonium changed to a tertiary amine due to a 1,4-addition reaction between the bisulfite and the quaternary ammonium salt. Thus, the chemical shift value of $\mathrm{H}_{\mathrm{b}}$ changed from $4.5 \mathrm{ppm}$ to $3.0 \mathrm{ppm}$. Meanwhile, the chemical shift value of $\mathrm{H}_{\mathrm{d}}$ moved from $8.2 \mathrm{ppm}$ to $5.0 \mathrm{ppm}$ because the conjugated bridge was broken. Moreover, due to the strong electron-withdrawing effect of bisulfite, a new signal peak at $4.7 \mathrm{ppm}\left(\mathrm{H}_{\mathrm{c}^{\prime}}\right)$ appeared. Thereby, the flow of electrons in the entire molecule was destroyed and the molecular fluorescence was quenched.

To further confirm the detection mechanism, Gaussian 09W software was used for theoretical calculations. As shown in Fig. S3 and S4, $\dagger$ the optimal configuration of Hcy-Mo and Hcy$\mathrm{Mo}+\mathrm{HSO}_{3}{ }^{-}$was obtained using density functional theory with 6-31G as the basis set. Significant optimal configuration differences appeared for $\mathbf{H c y}-\mathbf{M o}$ after the addition of $\mathrm{HSO}_{3}{ }^{-}$, including the breakage of the conjugated bridge, changes to bond angles, and removal of co-planarity between the electron donor and acceptor. Moreover, the results of LUMO and HOMO were visualized, as shown in Fig. S2. $\dagger$ The $\pi$ electrons in the HOMO of the probe were mainly located on the benzene ring and $\mathrm{N}$ atom of morpholine, while the electrons in the LUMO were situated on indolizidine. Thus, ICT occurred between the donor and acceptor units resulting in strong fluorescence. However, after treatment with bisulfite, the $\pi$ electrons in the $\mathrm{HOMO}$ of $\mathbf{H c y}-\mathbf{M o}+\mathrm{HSO}_{3}{ }^{-}$were located on bisulfite, while the electrons in the LUMO were positioned on the benzene ring. Therefore, the strong fluorescence emission disappeared because of the suppression of electron transfer.

\section{In vitro paper test}

Encouraged by the high sensitivity and selectivity of the Hcy-Mo probe, we evaluated its potential for the on-site visual detection of an aqueous solution using a colorimetric tube and probecoated test papers. As shown in Fig. S3, $\uparrow$ the color changed from brown to colorless with the addition of bisulfite but no color change was observed with the addition of other ions.

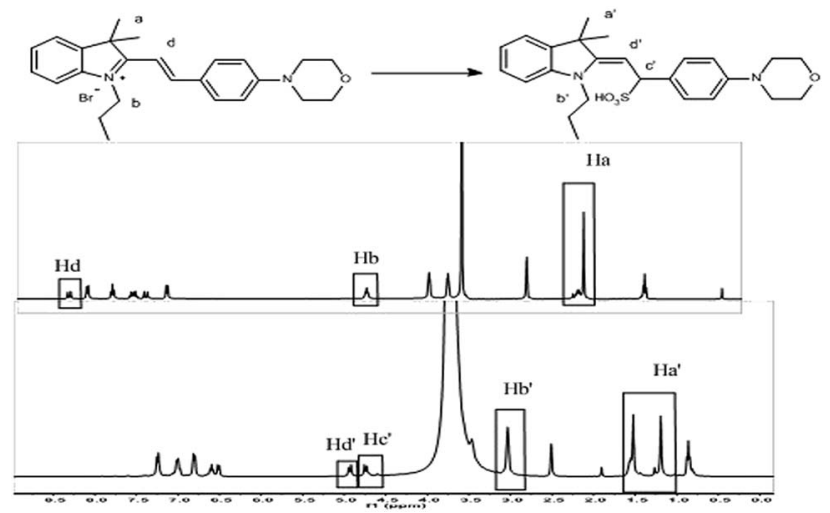

Fig. $4{ }^{1} \mathrm{H}$ NMR titration of Hcy-Mo probe with sodium bisulfite.

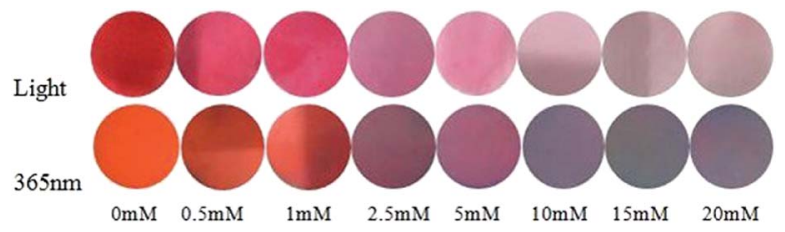

Fig. 5 Hcy-Mo $(1 \mathrm{mM})$ with different concentrations of sodium bisulfite $(0,0.5,1,2.5,5,10,15$, and $20 \mathrm{mM})$ in sunlight and $365 \mathrm{~nm}$ fluorescent light.

Moreover, as shown in Fig. 5, the color of the round test strips changed from brown to white with increasing concentration of bisulfite. Meanwhile, the color changed from purple to blue under a UV lamp (365 nm). Thus, the results showed that HcyMo possessed detection potential for bisulfite in aqueous solution.

\section{Cytotoxicity and cell imaging}

As mentioned above, to further explore the cytotoxicity and in vivo fluorescence imaging of the Hcy-Mo probe, cell imaging experiments were carried out. As shown in Fig. 6, strong red fluorescence was observed when the cells were incubated with a medium containing Hcy-Mo $(10 \mu \mathrm{M})$ for $30 \mathrm{~min}$. The red fluorescence disappeared after treatment with sodium bisulfite $(100 \mu \mathrm{M})$ for $5 \mathrm{~min}$. The results showed that Hcy-Mo has potential for in vivo experiments.

As shown in the MTT assay in Fig. S4, $\uparrow$ cell viability was reduced to less than $10 \%$ after $24 \mathrm{~h}$ of incubation at a concentration of $10 \mu \mathrm{M}$, which indicated that Hcy-Mo had low cytotoxicity towards MDA-MB-231 cells. Hence, Hcy-Mo shows potential for biological imaging.

\section{In vivo imaging experiments}

Encouraged by the promising profiles described above, in vivo imaging was carried out. Kunming mice, a typical experimental model, were divided into three groups as experimental subjects to explore the in vivo imaging effect of Hcy-Mo. The blank, control, and experimental group were injected with PBS, HcyMo $(50 \mu \mathrm{M})$, and Hcy-Mo $(50 \mu \mathrm{M})+\mathrm{HSO}_{3}{ }^{-}(500 \mu \mathrm{M})$, respectively. Tail vein injection was adopted as the injection method. As shown in Fig. 7, compared to the blank group, the control group showed strong fluorescence emission. At the same time, the fluorescence emission of the experimental group disappeared after treatment with bisulfite. In conclusion, the

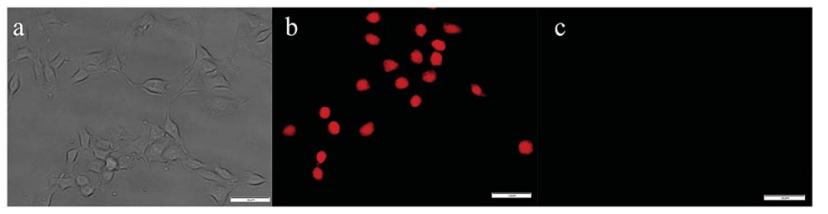

Fig. 6 Cell imaging of MDA-MB-231 cells treated with Hcy-Mo (10 $\mu \mathrm{M})$ in bright filed (a), absence (b) and presence (c) of sodium bisulfite $(100 \mu \mathrm{M})$ in the red channel $\left(\lambda_{\mathrm{ex}}=510 \mathrm{~nm}, \lambda_{\mathrm{em}}=580-660 \mathrm{~nm}\right)$ scale bar: $50 \mu \mathrm{m}$. 

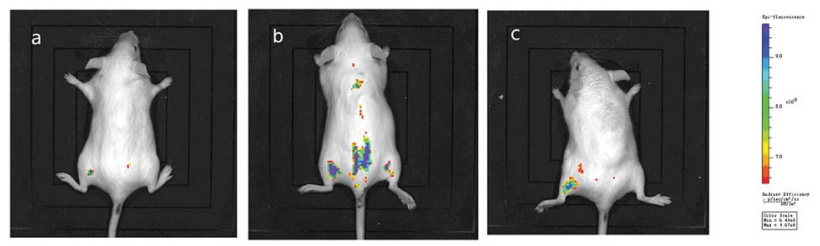

Fig. 7 (a) In vivo images of a mouse without the Hcy-Mo probe; (b) in vivo images of the mouse with the Hcy-Mo probe $(50 \mu \mathrm{M}, 20 \mu \mathrm{L})$ in the absence of bisulfite; (c) in vivo images of the mouse with Hcy-Mo after injection of $\mathrm{NaHSO}_{3}(500 \mu \mathrm{M}, 20 \mu \mathrm{L})$.

above data indicates that Hcy-Mo can be employed for the efficient detection of bisulfite in living mice.

\section{Conclusions}

In conclusion, based on a hemi-cyanine scaffold and morpholine group, a bisulfite fluorescent probe (Hcy-Mo) was designed and synthesized. Hcy-Mo shows promising profiles including a fast response (within $30 \mathrm{~s}$ ), good water solubility (in pure PBS), pH stability (7-9), and high sensitivity (LOD $=80 \mathrm{nM}$ ) and selectivity. In addition, low cytotoxicity and biological imaging potential are exhibited in MDA-MB-231 cells. Moreover, the detection of bisulfite in living mice was performed. The results of the experiments indicated that Hcy-Mo possessed live imaging potential, which provides a valuable tool for tracing the distribution and metabolism of bisulfite in biological systems.

\section{Conflicts of interest}

There are no conflicts to declare.

\section{Notes and references}

1 C. Winkler, B. Frick, K. Schroecksnadel, H. Schennach and D. Fuchs, Food Chem. Toxicol., 2006, 44, 2003-2007.

2 S. L. Taylor, N. A. Higley and R. K. Bush, Adv. Food Res., 1986, 30, 1-76.

3 A. Agar, V. Kucukatay, P. Yargicoglu, B. Aktekin, S. KipmenKorgun, D. Gumuslu and C. Apaydin, Arch. Environ. Contam. Toxicol., 2000, 39, 257-264.

4 Z. Meng, Inhalation Toxicol., 2003, 15, 181-195.

5 M. R. Lester, J. Am. Coll. Nutr., 1995, 14, 229-232.

6 J. A. Bernstein, N. Alexis, C. Barnes, I. L. Bernstein, J. A. Bernstein, A. Nel, D. Peden, D. Diaz-Sanchez, S. M. Tarlo and P. B. Williams, J. Allergy Clin. Immunol., 2004, 114, 1116-1123.

7 J. Sunyer, Eur. Heart J., 2003, 24, 752-760.

8 Z. Meng and B. Zhang, Mutagenesis, 2002, 17, 215-217.

9 Z. Meng, G. Qin, B. Zhang and J. Bai, Mutagenesis, 2004, 19, 465-468.

10 H. Jin, Y. Wang, X. Wang, Y. Sun, C. Tang and J. Du, Nitric Oxide, 2013, 32, 56-61.

11 N. Sang, Y. Yun, H. Li, L. Hou, M. Han and G. Li, Toxicol. Sci., 2010, 114, 226-236.
12 N. Sang, Y. Yun, G. Y. Yao, H. Y. Li, L. Guo and G. K. Li, Toxicol. Sci., 2011, 124, 400-413.

13 D. Q. Rich, J. Schwartz, M. A. Mittleman, M. Link, H. Luttmann-Gibson, P. J. Catalano, F. E. Speizer and D. W. Dockery, Am. J. Epidemiol., 2005, 161, 1123-1132.

14 W. J. Lee, K. Teschke, T. Kauppinen, A. Andersen, P. Jäppinen, I. Szadkowska-Stanczyk, N. Pearce, B. Persson, A. Bergeret, L. A. Facchini, R. Kishi, D. Kielkowski, B. A. Rix, P. Henneberger, J. Sunyer, D. Colin, M. Kogevinas and P. Boffetta, Environ. Health Perspect., 2002, 110, 991-995.

15 H. He, Y. Wang, Q. Ma, J. Ma, B. Chu, D. Ji, G. Tang, C. Liu, H. Zhang and J. Hao, Sci. Rep., 2014, 4, 4172.

16 A. Ağar, V. Küçükatay, P. Yargiçoğlu, B. Aktekin, S. KipmenKorgun, D. x Gümüșl and C. Apaydin, Arch. Environ. Contam. Toxicol., 2000, 39, 257-264.

17 S. Chirumbolo and G. Bjorklund, Front. Cardiovasc. Med., 2016, 3, 15.

18 Z. Li, Y. Huang, J. Du, A. D. Liu, C. Tang, Y. Qi and H. Jin, Int. J. Mol. Sci., 2016, 17, 266.

19 M. V. Navarrro, M. R. Payan, M. A. Lopez, R. FernandezTorres and M. C. Mochon, Talanta, 2010, 82, 2003-2006.

20 M. Koch, R. Koppen, D. Siegel, A. Witt and I. Nehls, J. Agric. Food Chem., 2010, 58, 9463-9467.

21 A. A. Salem, A. A. Soliman and I. A. El-Haty, Air Qual., Atmos. Health, 2009, 2, 133-145.

22 L. Chen, B. D. Borba and J. Rohrer, Determination of total and free sulfite in foods and beverages, Thermo Fisher Scientific, 2014.

23 D. Zhang, M. Pang, J. Wu and Y. Cao, New J. Chem., 2019, 43, 4900-4907.

24 X. Wang and Y. Liao, Appl. Phys. A: Mater. Sci. Process., 2019, $125,468$.

25 S. Sun, Q. Guan, Y. Liu, B. Wei, Y. Yang and Z. Yu, Chin. Chem. Lett., 2019, 30, 1051-1054.

26 Q. Wang, S. Zhang, B. Wang, X. Yang, B. Zou, B. Yang and S. Lu, Nanoscale Horiz., 2019, 4, 1227-1231.

27 Z. Chen, C. Wu, Z. Zhang, W. Wu, X. Wang and Z. Yu, Chin. Chem. Lett., 2018, 29, 1601-1608.

28 P. Zhao, Q. Xu, J. Tao, Z. Jin, Y. Pan, C. Yu and Z. Yu, Wiley Interdiscip. Rev.: Nanomed. Nanobiotechnol., 2018, 10, e1483.

29 Y. Urano, D. Asanuma, Y. Hama, Y. Koyama, T. Barrett, M. Kamiya, T. Nagano, T. Watanabe, A. Hasegawa, P. L. Choyke and H. Kobayashi, Tech. Rep., 2009, 15, 104-109.

30 T. Myochin, T. Nagano, K. Kiyose, K. Hanaoka, H. Kojima and T. Tera, J. Am. Chem. Soc., 2011, 133, 3401-3409.

31 L. Yuan, W. Lin, J. Song and Y. Yang, Chem. Commun., 2011, 47, 12691-12693.

32 L. Yuan, W. Lin, Y. Xie, B. Chen and S. Zhu, J. Am. Chem. Soc., 2012, 134, 1305-1315.

33 B. C. Dickinson, V. S. Lin and C. J. Chang, Nat. Protoc., 2013, 8, 1249-1259.

34 M. Y. Wu, K. Li, C. Y. Li, J. T. Hou and X. Q. Yu, Chem. Commun., 2014, 50, 183-185.

35 M. Y. Wu, T. He, K. Li, M. B. Wu, Z. Huang and X. Q. Yu, Analyst, 2013, 138, 3018-3025. 
36 P. Jana, N. Patel, V. Soppina and S. Kanvah, New J. Chem., 2019, 43, 584-592.

37 J. Wu, J. Pan, Z. Ye, L. Zeng and D. Su, Sens. Actuators, B, 2018, 274, 274-284.

38 J. Wang, L. Long and X. Xiao, Luminescence, 2016, 31, 775781.

39 G. Chen, W. Zhou, C. Zhao, Y. Liu, T. Chen, Y. Li and B. Tang, Anal. Chem., 2018, 90, 12442-12448.

$40 \mathrm{~S}$. Xu, R. Tang, Z. Wang, Y. Zhou and R. Yan, Spectrochim. Acta, Part A, 2015, 149, 208-215.

41 X. Liu, Q. Yang, W. Chen, L. Mo, S. Chen, J. Kang and X. Song, Org. Biomol. Chem., 2015, 13, 8663-8668.

42 J. Chao, Y. Liu, Y. Zhang, Y. Zhang, F. Huo, C. Yin, Y. Wang and L. Qin, Spectrochim. Acta, Part A, 2015, 146, 33-37.

43 Y. Yao, Q. Sun, Z. Chen, R. Huang, W. Zhang and J. Qian, Talanta, 2018, 189, 429-436.

44 T. Yu, G. Yin, T. Niu, P. Yin, H. Li, Y. Zhang, H. Chen, Y. Zeng and S. Yao, Talanta, 2018, 176, 1-7.

45 P. Chinna Ayya Swamy, G. Sivaraman, R. N. Priyanka, S. O. Raja, K. Ponnuvel, J. Shanmugpriya and A. Gulyani, Coord. Chem. Rev., 2020, 411, 1-51.

46 G.-J. Song, J. Luo, X.-j. Xing, H.-L. Ma, D. Yang, X.-Q. Cao, Y.-q. Ge and B.-X. Zhao, New J. Chem., 2018, 42, 3063-3068.
47 D. Li, Y. Shi, X. Tian, M. Wang, B. Huang, F. Li, S. Li, H. Zhou, J. Wu and Y. Tian, Sens. Actuators, B, 2016, 233, 1-6.

48 Y. Sun, S. Fan, S. Zhang, D. Zhao, L. Duan and R. Li, Sens. Actuators, B, 2014, 193, 173-177.

49 Y. Sun, D. Zhao, S. Fan, L. Duan and R. Li, J. Agric. Food Chem., 2014, 62, 3405-3409.

50 D. Zhang, A. Liu, R. Ji, J. Dong and Y. Ge, Anal. Chim. Acta, 2019, 1055, 133-139.

51 W. Xu, C. L. Teoh, J. Peng, D. Su, L. Yuan and Y. T. Chang, Biomaterials, 2015, 56, 1-9.

52 G. Wang, H. Chen, X. Chen and Y. Xie, RSC Adv., 2016, 6, 18662-18666.

53 J. Xu, J. Pan, X. Jiang, C. Qin, L. Zeng, H. Zhang and J. F. Zhang, Biosens. Bioelectron., 2016, 77, 725-732.

54 Y. Wang, Q. Meng, R. Zhang, H. Jia, C. Wang and Z. Zhang, J. Lumin., 2017, 192, 297-302.

55 S. O. Raja, G. Sivaraman, A. Mukherjee, C. Duraisamy and A. Gulyani, ChemistrySelect, 2017, 2, 4609-4616.

56 N. Velusamy, N. Thirumalaivasan, K. N. Bobba, S. Wu and S. Bhuniya, New J. Chem., 2018, 42, 1590-1594.

57 C. Wu, X. Hu, B. Gu, P. Yin, W. Su, Y. Li, Q. Lu, Y. Zhang and H. Li, Anal. Methods, 2018, 10, 604-610. 